\title{
Mitral valve operation in patients with the Marfan syndrome
}

Optimal surgical treatment of mitral regurgitation in the Marfan syndrome (valve repair versus replacement) is controversial because the underlying connective tissue defect theoretically might compromise repair durability. To examine the results of mitral valve repair in these patients, we did a retrospective review of 160 patients with the Marfan syndrome who had cardiac surgical procedures between January 1983 and January 1993. Thirty-six patients had mitral procedures, 29 of which were repairs. Mitral valve replacement was necessary in seven patients because of extensive annular calcification and/or severe anterior leaflet abnormalities. The 18 men and 11 women undergoing mitral valve repair had a mean age of $26.5 \pm \mathbf{2 . 6}$ years (range 9 months to 54 years); seven patients were less than 18 years of age. Twenty-four of the 29 patients had concomitant aortic root replacement because of aortic dilation or valvular insufficiency. All 29 repairs included annuloplasty, and 11 patients also required leaflet resection. There were no operative deaths. At mean follow-up of $26.6 \pm 4.8$ months, there have been three late deaths, two caused by arrhythmia and one by complications of type III aortic dissection. All survivors are in New York Heart Association class I or II. In three patients recurrent mitral regurgitation developed (grade III or IV); 5-year actuarial freedom from significant mitral regurgitation was $88.3 \%$. One patient required repeat mitral annuloplasty after endocarditis of the composite aortic graft spread to the mitral valve. No patient required late mitral valve replacement. These results demonstrate that (1) $22 \%$ of patients with the Marfan syndrome who undergo cardiac operation require a mitral valve procedure, (2) most can be treated by mitral repair rather than replacement, and (3) at early follow-up, results of mitral repair in this population are satisfactory. ( $J$ Thorac Cardiovasc Surg 1994;107:724-31)

A. Marc Gillinov, MD, Atul Hulyalkar, MD, Duke E. Cameron, MD, Peter W. Cho, MD, Peter S. Greene, MD, Bruce A. Reitz, MD, Reed E. Pyeritz, MD, PhD, and

Vincent L. Gott, MD, Baltimore, $M d$.

$\mathrm{T}_{\text {he }}$ Marfan syndrome is the most common heritable disorder of connective tissue and is characterized by car-

From the Division of Cardiac Surgery, the Division of Cardiac Anesthesia, and the Center for Medical Genetics, The Johns Hopkins Medical Institutions, Baltimore, Md.

Supported by U.S. Public Health Service National Institutes of Health grant HL35877 and the National Marfan Foundation.

Presented in part at the Forty-Second Annual Scientific Session of the American College of Cardiology, Anaheim, Calif., March 14-18, 1993.

Received for publication April 20, 1993.

Accepted for publication Aug. 17, 1993.

Address for reprints: Duke E. Cameron, MD, The Johns Hopkins Hospital, 600 N. Wolfe St.-Blalock 618, Baltimore, MD 21287.

Copyright $(1994$ by Mosby-Year Book, Inc.

$0022-5223 / 94 \$ 3.00+0 \quad 12 / 1 / 50819$ diovascular, skeletal, and ocular abnormalities.1,2 untreated, cardiovascular manifestations of the Marfa syndrome cause death in one half of patients during th first four decades of life. ${ }^{3}$ Although aortic root dilatio and aortic valve regurgitation are responsible for most c the serious morbidity and mortality, $80 \%$ of patients wit the Marfan syndrome have mitral valve dysfunction. ${ }^{4}$, Furthermore, mitral valve disease is the most commo cause of morbidity and mortality in infants with th Marfan syndrome. ${ }^{6-9}$

Echocardiographic studies demonstrate mitral vals prolapse in $60 \%$ to $80 \%$ of patients with the Marfan syı drome. ${ }^{4,10}$ Although these patients are usually free symptoms, the mitral valve dysfunction is often progre sive. By age 30 , one in eight patients with the Marfa syndrome will have moderate to severe mitral regurgit: 
tion (MR). ${ }^{4}$ When MR occurs, pathologic findings of the mitral valve include annular dilation, calcium deposition, fibromyxomatous changes in leaflets and chordae, and elongation and rupture of chordae. ${ }^{4,5,11}$ Anterior leaflet abnormalities, annular dilation, and the ventricular remodeling that occurs after correction of aortic insufficiency make mitral valve repair in this patient population particularly challenging. $4,5,11,12$

Although mitral valve repair techniques have gained wide acceptance, there have been no reports of the results of mitral valve repair in patients with the Marfan syndrome. Of 160 patients with the Marfan syndrome who underwent cardiac surgical procedures at The Johns Hopkins Hospital between January 1983 and January 1993, 36 had mitral valve procedures: 29 had mitral valve repair and seven had mitral valve replacement (MVR). This review was undertaken to determine the results of mitral valve operations in patients with the Marfan syndrome.

\section{Methods}

Patient selection and data collection. More than 400 patients with the Marfan syndrome are evaluated each year in the Center for Medical Genetics of The Johns Hopkins Hospital; $90 \%$ of the patients in this series were referred from that clinic. Between January 1983 and January 1993, 160 patients with the Marfan syndrome underwent cardiac surgical procedures. Review of operative notes revealed that 36 of these patients had mitral valve procedures, and these patients form the subject of this report. All patients met standard diagnostic criteria for the Marfan syndrome, which include family history and characteristic cardiovascular, skeletal, and ocular manifestations. $^{2}$

Data were collected from clinic notes, operative reports, perfusion records, and follow-up with the patient or cardiologist. Echocardiograms or reports were available for 35 of 36 patients preoperatively and for 33 of 36 postoperative patients. Echocardiograms were done with Hewlett-Packard SONOS 500 or SONOS 1000 ultrasound imaging systems (Hewlett-Packard Company, Andover, Mass.) with $2.5 \mathrm{MHz}$ or $3.5 \mathrm{MHz}$ handheld probes. Standard echocardiographic images were obtained including parasternal short axis, long axis, and apical two- and four-chamber views. Color Doppler imaging was used to assess severity of mitral regurgitation in standard fashion ( 0 to $4+$ ). All patients were seen 1 month after hospital discharge, and late follow-up was available in 33 of 36 patients.

Operative techniques. Standard hypothermic $\left(28^{\circ} \mathrm{C}\right) \mathrm{car}-$ diopulmonary bypass and crystalloid potassium cardioplegic arrest were used for all cases. Continuous high-flow $4^{\circ} \mathrm{C}$ topical saline lavage was also used for myocardial protection. Replacement of the aortic root by a modified Bentall technique was done in 27 patients; details of this operation are described elsewhere. ${ }^{13}$ Patients who required mitral valve procedures had bicaval cannulation for venous return, and most patients had femoral arterial cannulation to avoid surgical trauma to the distal ascending aorta.
Table I. Mitral valve operation in the Marfan syndrome (36 patients)

\begin{tabular}{lc}
\hline \multicolumn{1}{c}{ Operation } & No. of patients \\
\hline Mitral valve repair/aortic root replacement & 24 \\
Mitral valve repair alone & 5 \\
MVR/aortic root replacement & 3 \\
MVR alone & 4 \\
\hline
\end{tabular}

Before 1988, mitral valve competence was assessed intraoperatively by observing leaflet coaptation after distention of the left ventricle with saline. Since 1988 , we have also used intraoperative transesophageal echocardiography to assess valve function before and after removal of the aortic crossclamp.

Postoperative care. All patients who received composite aortic grafts (20) or prosthetic mitral valves (6) have continued to receive sodium warfarin. Patients who underwent isolated mitral valve repair (5), mitral valve repair and replacement of the aortic root with homograft (4), or MVR with a tissue valve (1) received sodium warfarin for 6 weeks after operation. Patients who had aortic root procedures were also given $\beta$-adrenergic blocking agents. All patients followed up in the medical genetics clinic had biannual physical examination, annual magnetic resonance imaging of the aorta, and annual Doppler echocardiograms.

Statistical analysis. Preoperative and postoperative New York Heart Association (NYHA) functional class and grade of MR were compared by the Wilcoxon test. The Kaplan-Meier method was used to calculate actuarial probability of survival and freedom from morbid events.

\section{Results}

Operative results. Of 160 patients with the Marfan syndrome who underwent cardiac operation during the 10-year period, 36 had mitral valve procedures (Fig. 1). In 27 of those 36 patients, aortic valve or aortic root disease was the primary indication for operation and aortic root replacement was done concomitantly with a mitral valve procedure. Mitral valve repair was possible in 29 of 36 patients (Table I). In seven patients, heavy annular calcification and/or severe anterior leaflet abnormalities with multiple ruptured chordae precluded valve repair. Six of seven patients who had MVR received St. Jude Medical valves (St. Jude Medical, Inc., St. Paul, Minn.); the seventh patient, a young woman of child-bearing age, received a tissue valve.

Mean age of patients undergoing mitral valve repair was $26.5 \pm 2.6$ years (range 9 months to 54 years). Eighteen patients were male and 11 were female. At operation, all patients had annular dilation (mitral valve anulus diameter 4 to $8 \mathrm{~cm}$ ) and 28 of 29 patients had mitral valve prolapse. Two patients who had mitral valve repair had ruptured posterior chordae and one had rup- 


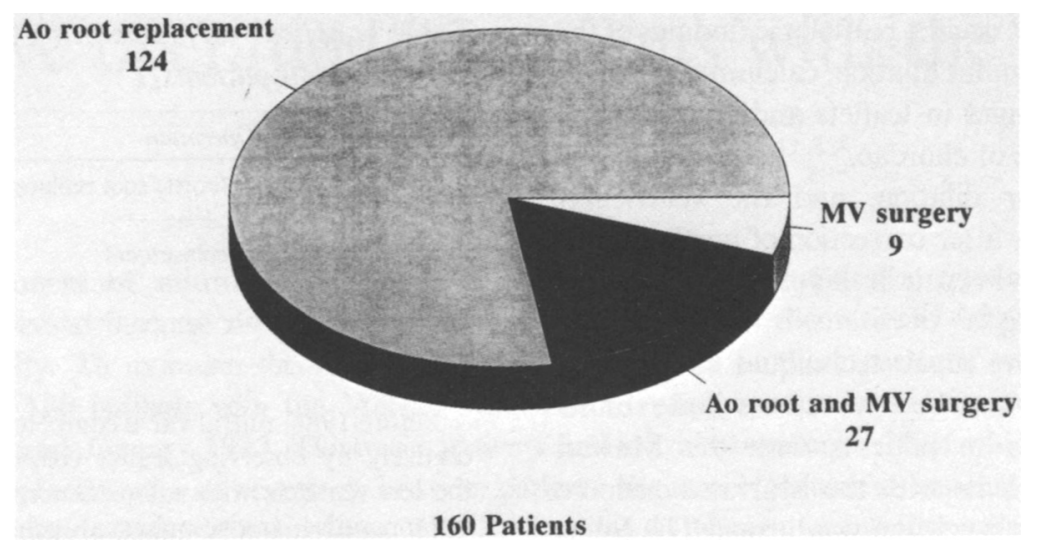

Fig. 1. Cardiac surgical procedures in 160 patients with Marfan syndrome over 10-year period. Aoroot, Aortic root replacement; $M V$, mitral valve.

Table II. Mitral valve repair: operative techniques

\begin{tabular}{|c|c|}
\hline Operative technique & No. of patients \\
\hline Annuloplasty & 29 \\
\hline Flexible ring (Duran) & 18 \\
\hline Rigid ring (Carpentier) & 7 \\
\hline Other & 4 \\
\hline Leaflet resection & 11 \\
\hline Posterior & 9 \\
\hline Anterior & 1 \\
\hline Posterior and anterior & 1 \\
\hline
\end{tabular}

tured anterior chordae. Mild to moderate annular calcification was present in two patients who received repair.

Operative techniques for mitral valve repair used in this series are listed in Table II. All patients had mitral annuloplasty and most received Duran flexible annuloplasty rings. Carpentier rigid rings were placed in seven patients and Puig-Massana-Shiley rings (Shiley, Inc., Irvine, Calif.) in two. One patient had a De Vega mitral annuloplasty. One patient with massive mitral annular dilation had a specially tailored "designer" annuloplasty ring made of polytetrafluoroethylene. ${ }^{* 14}$ Leaflet resection was done in 11 patients, including the three patients with ruptured chordae. Two patients had De Vega tricuspid annuloplasty in addition to aortic root replacement and mitral valve repair. One patient had closure of an ostium secundum atrial septal defect. Mean cardiopulmonary bypass and aortic crossclamp times for patients undergoing mitral valve repair and aortic root replacement were $183.8 \pm 5.9$ minutes and $129.1 \pm 6.6$ minutes, respec-

${ }^{*}$ Gore-Tex, W.L. Gore \& Associates, Inc., Elkton, Md. tively. For patients undergoing isolated mitral valve repair, mean bypass time was $95.8 \pm 4.8$ minutes and aortic crossclamp time was $68.2 \pm 3.1$ minutes.

There were no operative deaths among patients who underwent mitral valve repair or MVR. In one patient who had MVR and composite graft replacement of the aortic root intractable ventricular arrhythmias and severe biventricular failure developed early after operation. $\mathrm{He}$ was supported with biventricular centrifugal assist devices and was subsequently weaned from circulatory support. He was discharged from the hospital and remains well as last follow-up. There were no other instances of postcardiotomy cardiogenic shock.

Late results. Mean follow-up was $26.6 \pm 4.8$ months (range 1 month to 8 years) for patients who underwent mitral repair and 29.2 \pm 13.1 months (range 1 month to 7.5 years) for patients who underwent MVR. All patients were seen 1 month after hospital discharge, but two patients with mitral repair and one with MVR were lost in late follow-up. There have been three late deaths among patients who received mitral repair; two were due to arrhythmia and one was the result of type III aortic dissection that occurred 3 years after mitral valve repair. Actuarial 5-year survival after mitral valve repair was $76.7 \%$ (Fig. 2). One patient who had MVR alone died of acute type I aortic dissection 2 years after operation.

The degree of preoperative and late postoperative MR among patients who received mitral repair is depicted in Fig. 3. Preoperatively, $76 \%$ of patients had 3 or $4+$ MR; the remaining $24 \%$ had $2+$ MR. Echocardiograms from the immediate postoperative period demonstrated improvement in MR in all patients. At late follow-up, three patients have recurrent MR ( 3 or $4+$ ). One of these patients had a De Vega type mitral annuloplasty with a 


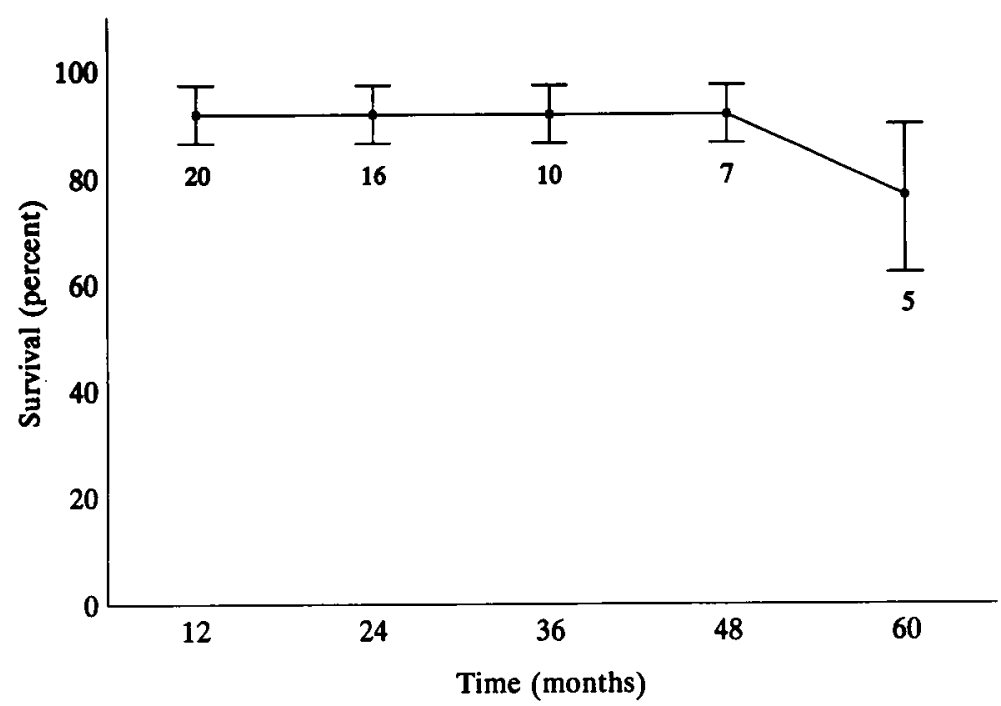

Fig. 2. Actuarial probability of survival after mitral valve repair. Error bars indicate $70 \%$ confidence intervals. Number of patients entering each time interval is indicated beneath each point.

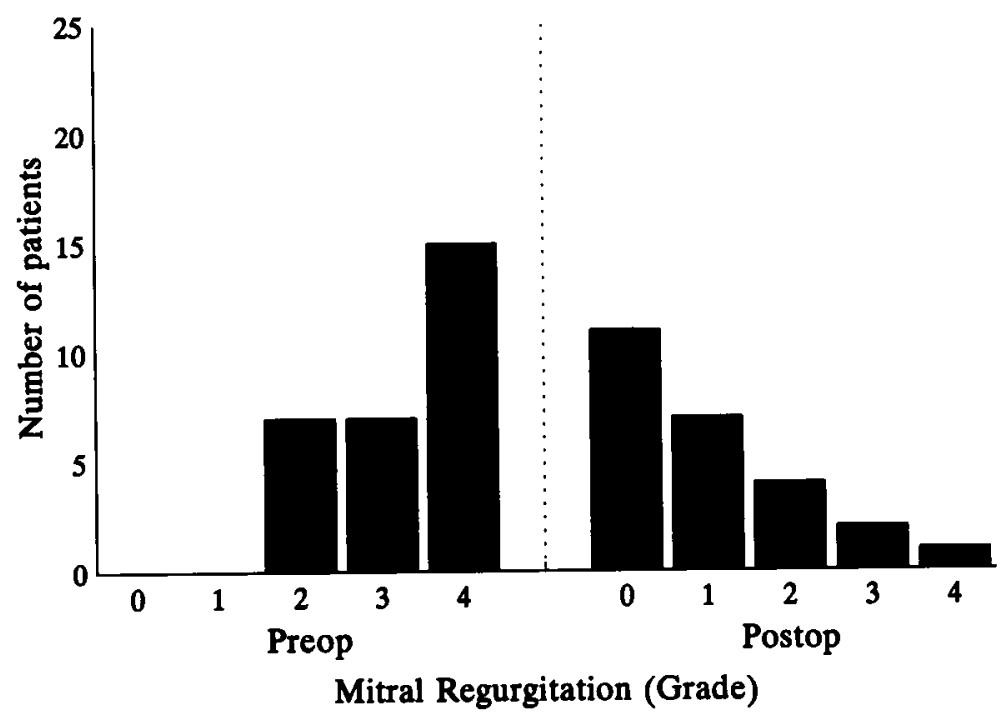

Fig. 3. Preoperative and postoperative grades of $\mathrm{MR}$ after mitral valve repair. 1,2,3, and 4 refer to mild, moderate, moderately severe, and severe MR by Doppler echocardiography, respectively $(p<0.0005$ for preoperative versus postoperative grade of $M R$ ).

stable result for 5 years; however, 6 years after operation $3+$ MR developed. This patient remains in NYHA functional class I. A second patient had a Duran mitral annuloplasty with early success but $4+$ MR developed 2 years later; she is also in NYHA functional class I. The third patient had a large mitral anulus $(6 \mathrm{~cm})$ and underwent Duran annuloplasty. Intraoperative transesophageal echocardiography demonstrated residual 1 to 2+ MR. Eigh- teen months later, he had 3+ MR and was in NYHA functional class II.

Overall, 5-year actuarial freedom from significant MR ( 3 or $4+$ ) after mitral valve repair was $88.3 \%$ (Fig. 4). No patient who had mitral valve repair has required further mitral valve operation for recurrent $M R$. One patient who had a bioprosthetic MVR required MVR with a St. Jude Medical prosthesis for bioprosthetic degeneration at 7 


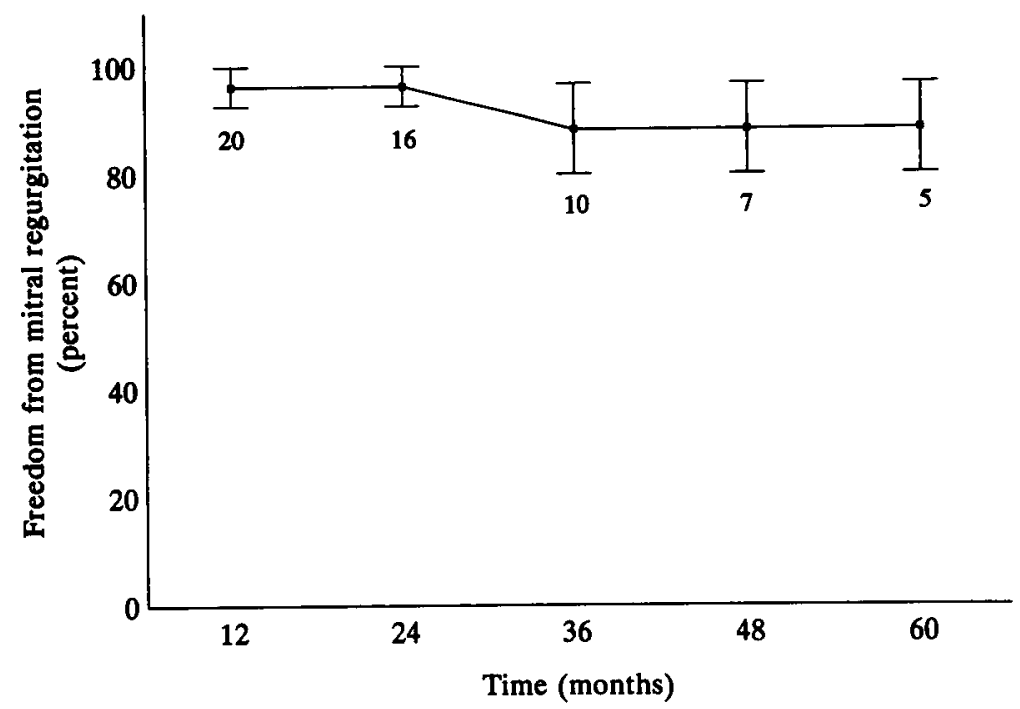

Fig. 4. Actuarial probability of freedom from significant MR after mitral valve repair. Error bars indicate $70 \%$ confidence intervals. Number of patients entering each time interval is indicated beneath each point.

years. All other living MVR patients are in NYHA class I or II and free from significant MR at last follow-up.

In late follow-up, there was only one episode of endocarditis. A patient who underwent mitral repair and aortic root replacement had aortic graft endocarditis. He had a second composite graft placed but recurrent endocarditis developed 10 months later. At the third operation, the aortic root was replaced by a homograft; intraoperative transesophageal echocardiography demonstrated 1 to $2+$ MR with dehiscence of the Carpentier mitral ring. There was no infection of the mitral anulus, so the Carpentier ring was removed and a Duran ring was placed. This patient has done well and is free of endocarditis and MR 44 months later. Because this was the only patient with mitral valve repair who required further mitral valve operation, the 5-year actuarial freedom from reoperation was $94 \%$ (Fig. 5).

Before mitral valve repair, more than half of the patients were in NYHA functional class III or IV; at last follow-up, all surviving patients were in class I or II (Fig. 6). In three patients with atrial fibrillation before mitral valve repair, conversion to normal sinus rhythm has occurred in two, whereas atrial fibrillation persists in one. The patient in whom endocarditis developed has thirddegree heart block and is pacemaker-dependent.

Echocardiographic evidence of left ventricular outflow tract obstruction developed in one patient because of systolic anterior motion of the mitral valve after Duran annuloplasty. Although free of symptoms, this patient had a peak gradient of $55 \mathrm{~mm} \mathrm{Hg}$ by Doppler echocardiography 1 month after operation. An echocardiogram
6 months after operation demonstrated resolution of systolic anterior motion.

\section{Discussion}

The Marfan syndrome is a heritable disorder of connective tissue caused by mutation in the fibrillin gene on chromosome $15 .{ }^{15}$ The connective tissue defect results in characteristic cardiovascular, ocular, and skeletal abnormalities. ${ }^{1,2}$ Murdoch and associates ${ }^{3}$ demonstrated that early mortality in patients with the Marfan syndrome is attributable to cardiovascular manifestations of the disease. Aortic dilation and its complications account for most significant morbidity and mortality among these patients. ${ }^{3}$ Gott and associates, ${ }^{13}$ Svensson and associates, ${ }^{16}$ Kouchoukos, Marshall, and Wedige-Stecher, ${ }^{17}$ and others ${ }^{18}$ have demonstrated that composite replacement of the aortic root may be accomplished with low morbidity and mortality in these patients.

Although aortic root dilation and aortic regurgitation are the most prominent cardiovascular features in the Marfan syndrome, mitral valve disease occurs with considerable frequency. $4,5,10$ Echocardiography reveals mitral valve dysfunction in $60 \%$ to $80 \%$ of patients with the Marfan syndrome. ${ }^{4,5,10}$ Most of these patients have mitral valve prolapse without symptoms. In a longitudinal 4-year study of 166 patients with the Marfan syndrome, Pyeritz and Wappel ${ }^{4}$ found that clinically significant MR developed in 14\%. MR is also the leading cause of morbidity and mortality in infants and small children with the Marfan syndrome. ${ }^{6-9}$

Structural alterations of the mitral valve in patients 


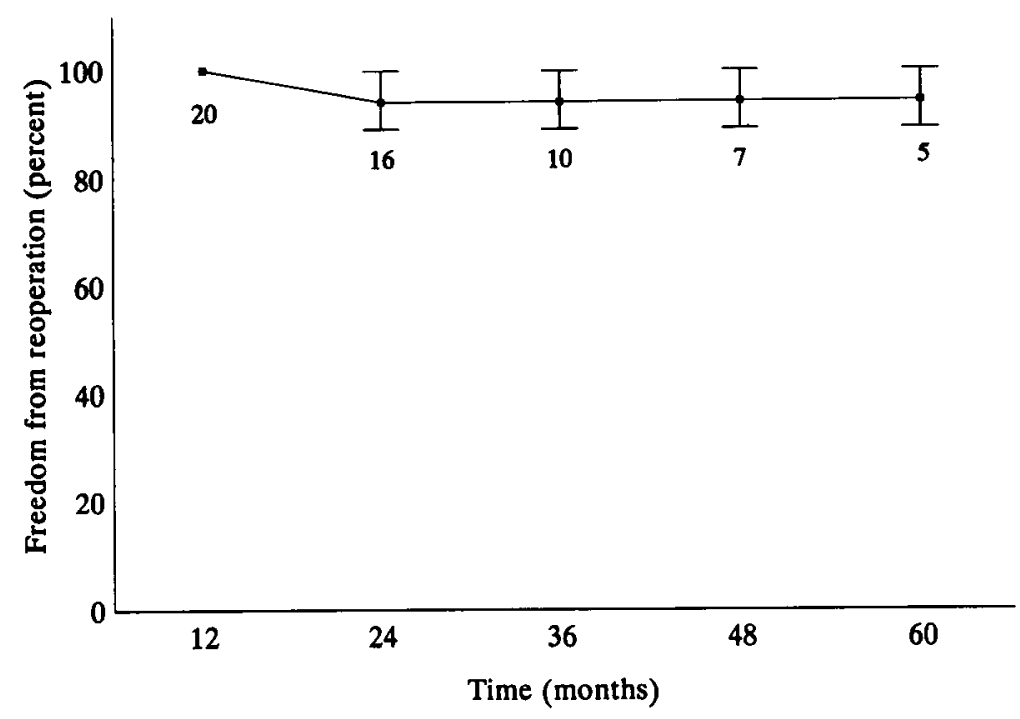

Fig. 5. Actuarial probability of freedom from reoperation on mitral valve after mitral valve repair. Error bars indicate $70 \%$ confidence intervals. Number of patients entering each interval is indicated beneath each point.

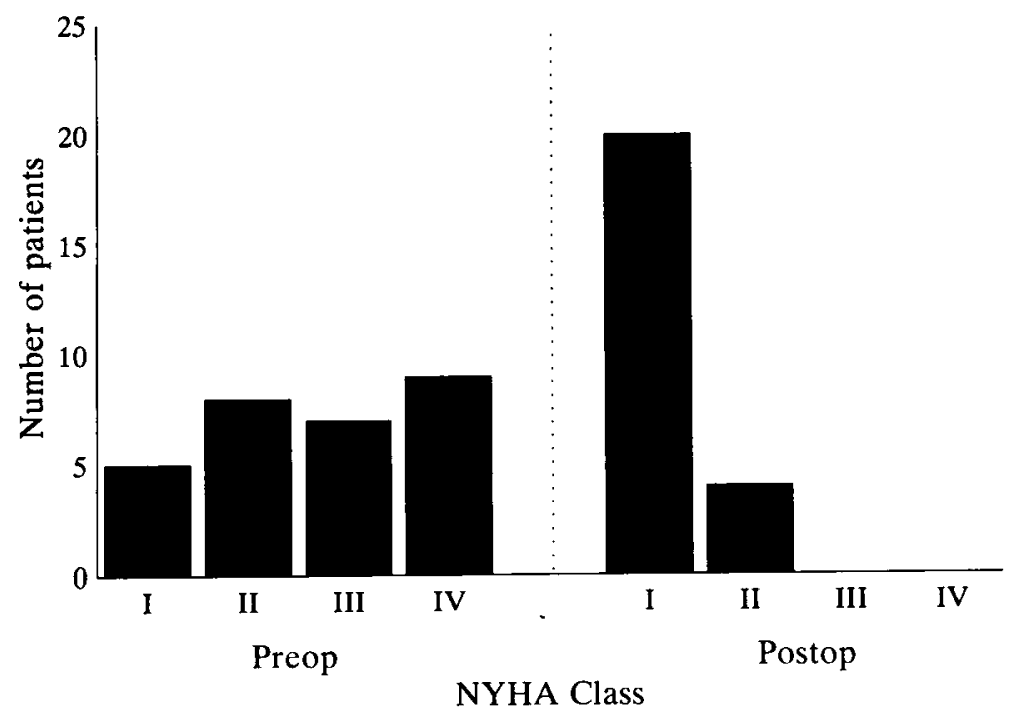

Fig. 6. Preoperative and postoperative NYHA functional classes after mitral valve repair $(p<0.0005$ for preoperative versus postoperative NYHA class).

with the Marfan syndrome include annular dilation, annular calcification, fibromyxomatous changes of leaflets and chordae, chordal rupture and elongation, and leaflet fenestration. $4,5,11$ The latter finding may represent residua of endocarditis. ${ }^{4}$ Pini and associates ${ }^{10}$ have recently demonstrated that $15 \%$ of patients with the Marfan syndrome have abnormal chordal attachments whereby posterior leaflet chordae arise atypically from the posterior ventricular wall.

Dietzman and colleagues ${ }^{19}$ reported the first successful MVR in a patient with the Marfan syndrome in 1967.
The following year, Sirak and Ressallat ${ }^{20}$ provided late follow-up data for two patients with the Marfan syndrome in whom they attempted mitral valve repair. Using suture annuloplasty and posterior leaflet plication, they achieved temporary reduction of MR in both patients. Because MR recurred in both patients within 2 years, they concluded that the underlying tissue defect prohibited durable repair. Other authors subsequently concurred with this conclusion, ${ }^{21}$ and MVR became the accepted treatment of MR in the patient with the Marfan syndrome. 
Advances in mitral valve repair techniques have led to reexamination of optimal surgical therapy for MR in these patients. In 1971, Carpentier and associates ${ }^{22}$ described a new reconstructive operation for MR in which the anulus is remodeled with a semirigid ring. Since that time, Carpentier and his colleagues ${ }^{23-25}$ and others ${ }^{26-28}$ have developed a variety of techniques for repair of the mitral anulus, leaflets, and subvalvular apparatus. Early and long-term results of mitral valve reconstruction have been excellent. ${ }^{22-31}$ Reoperation is infrequent, and endocarditis, thromboembolism, and anticoagulant-related hemorrhage are less frequent after repair than replacement. ${ }^{22-31}$ In addition, mitral valve repair preserves the subvalvular apparatus, which may be important to left ventricular function. ${ }^{29,32}$ In general, mitral valve repair has been most durable in patients with degenerative valve disease. ${ }^{23-25,27,30}$ This latter finding suggests that patients with the Marfan syndrome might fare well with application of newer techniques of mitral valve repair.

Over a 10-year period, 36 of 160 patients with the Marfan syndrome who had cardiac operations at The Johns Hopkins Hospital had mitral valve procedures. Aortic root disease was the primary indication for operation in 27 of these 36 patients. Pyeritz and Wappel ${ }^{4}$ have demonstrated that mitral valve dysfunction is progressive in $56 \%$ of patients with the Marfan syndrome. Therefore, in the setting of aortic root replacement, our policy has been to attempt mitral valve repair when MR is $2+$ or greater. Mitral repair can be done quickly and safely in these patients, and it may obviate the need for further cardiac operations to correct progressive mitral dysfunction. Of the 36 patients who had mitral valve operations, 29 had 3 or $4+$ MR and 7 had 2+ MR. All valves were considered for repair, but seven patients had MVR rather than repair because of extensive annular calcification or severe anterior leaflet abnormalities. These circumstances generally favor valve replacement rather than repair. ${ }^{28}$

From our experience, it appears that mitral valve repair can be done in $80 \%$ of patients with the Marfan syndrome who undergo mitral valve procedures. Others have found a similar proportion of reparable valves among patients with degenerative mitral valve disease. ${ }^{23,27,29}$ As noted earlier, advantages of mitral valve repair over replacement include preservation of the subvalvular apparatus and a lower risk of endocarditis. ${ }^{25,27,29,31}$ In addition, those patients who underwent isolated mitral valve repair or combined mitral valve repair and replacement of the aortic root with homograft (total of seven patients) were spared long-term anticoagulation. These observations support our strategy for favoring mitral valve repair over valve replacement in this population.

There was no operative mortality in this series and none of the three late deaths was attributable to mitral valve dysfunction. No patient has required late MVR after repair. However, three patients have 3 or $4+M R$ at last follow-up. In two of these patients, surgical technique (ring annuloplasty rather than De Vega annuloplasty in one and mural leaflet resection in another) might have improved repair durability. Still, actuarial 5-year freedom from recurrent MR is $88.3 \%$. In patients without the Marfan syndrome, Carpentier and colleagues ${ }^{24}$ reported $89 \%$ freedom from reoperation 9 years after repair and Cosgrove and associates ${ }^{29}$ noted a 2-year actuarial freedom from reoperation of $96.1 \%$. Comparison of our results with these studies must take into account that nearly one quarter of our patients had only $2+\mathrm{MR}$; although we repair such valves in the setting of concomitant aortic root replacement, patients with this degree of MR would not usually be included in mitral repair series of patients without the Marfan syndrome.

Mitral valve repair in patients with the Marfan syndrome offers a challenge to the surgeon. Pronounced annular dilation, anterior leaflet disease, and ventricular remodeling that occurs after aortic root replacement can complicate mitral valve repair. ${ }^{4,5,12}$ Nevertheless, repair is possible in $80 \%$ of patients with the Marfan syndrome. At intermediate follow-up, repair durability is satisfactory. Although long-term follow-up is not yet available, we currently recommend that patients with the Marfan syndrome who undergo aortic root replacement have concomitant mitral valve repair if MR is $2+$ or greater and that mitral repair is the treatment of choice for isolated $3+$ or $4+\mathrm{MR}$.

\section{REFERENCES}

1. Pyeritz RE, McKusick VA. The Marfan syndrome: diagnosis and management. N Engl J Med 1979;300:772-7.

2. Beighton $P$, de Paepe A, Danks G, et al. International nosology of heritable disorders of connective tissue, Berlin, 1986. Am J Med Genet 1988;29:581-94.

3. Murdoch JL, Walker BA, Halpern BL, Kuzma JW, McKusick VA. Life expectancy and causes of death in the Marfan syndrome. N Engl J Med 1972;286:804-8.

4. Pyeritz RE, Wappel MA. Mitral valve dysfunction in the Marfan syndrome. Am J Med 1983;74:797-807.

5. Hirata K, Triposkiadis F, Sparks E, Bowen J, Boudoulas H, Wooley CF. The Marfan syndrome: cardiovascular physical findings and diagnostic correlates. Am Heart J 1992;123:743-52.

6. Sisk HE, Zahka KG, Pyeritz RE. The Marfan syndrome 
in early childhood: analysis of 15 patients diagnosed at less than 4 years of age. Am J Cardiol 1983;52:353-8.

7. Geva T, Hegesh J, Frand M. The clinical course and echocardiographic features of Marfan's syndrome in childhood. Am J Dis Child 1987;141:1179-82.

8. Phornphutkul C, Rosenthal A, Nadas AS. Cardiac manifestations of Marfan syndrome in infancy and childhood. Circulation 1973;47:587-96.

9. Morse RP, Rockenmacher S, Pyeritz RE, et al. Diagnosis and management of infantile Marfan syndrome. Pediatrics 1990;86:888-95.

10. Pini R, Roman MJ, Kramer-Fox R, Devereux RB. Mitral valve dimensions and motion in Marfan patients with and without mitral valve prolapse. Circulation 1989;80:915-24.

11. Roberts WC, Honig HS. The spectrum of cardiovascular disease in the Marfan syndrome: a clinico-morphologic study of 18 necropsy patients and comparison to 151 previously reported necropsy patients. Am Heart J 1982;104: 115-35.

12. Lima SD, Lima JAC, Pyeritz RE, Weiss JL. Relation of mitral valve prolapse to left ventricular size in Marfan's syndrome. Am J Cardiol 1985;55:739-43.

13. Gott VL, Pyeritz RE, Cameron DE, Greene PS, McKusick VA. Composite graft repair of Marfan aneurysm of the ascending aorta: results in 100 patients. Ann Thorac Surg 1991;52:38-45.

14. Shumway SJ, Gott VL, Reitz BA. A “designer" annuloplasty ring for patients with massive mitral annular dilatation. Ann Thorac Surg 1988;46:695-6.

15. Tsipouras P, Del Mastro R, Sarfarazi M, et al. Genetic linkage of the Marfan syndrome, ectopia lentis, and congenital contractural arachnodactyly to the fibrillin genes on chromosomes 15 and 5. N Engl J Med 1992;326:905-9.

16. Svensson LG, Crawford ES, Coselli JS, Safi HJ, Hess KR. Impact of cardiovascular operation on survival in the Marfan patient. Circulation 1989;80(Suppl):I233-42.

17. Kouchoukos NT, Marshall WG, Wedige-Stecher TA. Eleven-year experience with composite graft replacement of the ascending aorta and aortic valve. J THORAC CARDIOVASC SURG 1986;92:691-705.

18. Cabrol C, Pavie A, Mesnildrey P, et al. Long-term results with total replacement of the ascending aorta and reimplantation of the coronary arteries. J THORAC CARDIOVASC SuRG 1986;91:17-25.
19. Dietzman RH, Peter ET, Wang Y, Lillehei RC. Mitral insufficiency in Marfan syndrome. Dis Chest 1967;51:6508.

20. Sirak HD, Ressallat MM. Surgical correction of mitral insufficiency in Marfan's syndrome. J THORAC CARDIOvASC SURG 1967;55:493-500.

21. Nelson RM, Vaughn CC. Double valve replacement in Marfan's syndrome. J ThoraC CardiovasC SuRg 1968; 57:732-7.

22. Carpentier A, Deloche A, Dauptain J, et al. A new reconstructive operation for correction of mitral and tricuspid insufficiency. J THORAC CARDIOVASC SURG 1971;61:1-13.

23. Carpentier A. Cardiac valve surgery: the "French correction." J Thorac Cardiovasc Surg 1983;86:323-37.

24. Carpentier A, Chauvaud S, Fabiani JN, et al. Reconstructive surgery of mitral valve incompetence. J THORAC CARDIOVASC SURG 1980;79:338-48.

25. Deloche A, Jebara VA, Relland JYM, et al. Valve repair with Carpentier techniques. J THORAC CARdIOVASC SURG 1990;99:990-1002.

26. Duran CG, Ubago JLM. Clinical and hemodynamic performance of a totally flexible prosthetic ring for atrioventricular valve reconstruction. Ann Thorac Surg 1976;22: 458-63.

27. Duran CMG. Perspectives in reparative surgery for acquired valvular disease. Adv Cardiac Surg 1993;4:1-23.

28. Murphy JP Jr, Sweeney MS, Cooley DA. The Puig-Massana-Shiley annuloplasty ring for mitral valve repair: experience in 126 patients. Ann Thorac Surg 1987;43:52-8.

29. Cosgrove DM, Chavez AM, Lytle BW, et al. Results of mitral valve reconstruction. Circulation 1986;74(Suppl): I82-7.

30. Galloway AC, Colvin SB, Baumann FG, et al. Long-term results of mitral valve reconstruction with Carpentier techniques in 148 patients with mitral insufficiency. Circulation 1988;78(Suppl):I97-105.

31. Cohn LH, Kowalker W, Bhatia S, et al. Comparative morbidity of mitral valve repair versus replacement for mitral regurgitation with and without coronary artery disease. Ann Thorac Surg 1988;45:284-90.

32. David TE, Komeda M, Pollick C, Burns RJ. Mitral valve annuloplasty: the effect of the type on left ventricular function. Ann Thorac Surg 1989;47:524-8. 